\title{
Correction to: Metal accumulation and health risk assessment in wastewater used for irrigation around the Agra Canal in Faridabad, India
}

\author{
Akanksha Verma ${ }^{1}$. Usha Singh Gaharwar ${ }^{1} \cdot$ Eepsita Priyadarshini $^{1} \cdot$ Paulraj Rajamani $^{1}$ \\ Published online: 30 December 2021 \\ ๑) Springer-Verlag GmbH Germany, part of Springer Nature 2021
}

\section{Correction to: Environmental Science and Pollution Research} https://doi.org/10.1007/s11356-021-16088-3

In the published proof, a typographical error have been noted which could cause difficulty for readers.

The error and corrected text are listed below:

Error: $\mathrm{HClO}_{4}, \mathrm{HNO}_{3}$, and $\mathrm{HClO}_{4}$.

Corrected text : $\mathrm{HNO}_{3}, \mathrm{H}_{2} \mathrm{SO}_{4}$, and $\mathrm{HClO}_{4}$

It was mentioned twice at page 4 .

Publisher's note Springer Nature remains neutral with regard to jurisdictional claims in published maps and institutional affiliations.

The original article can be found online at https://doi.org/10.1007/ s11356-021-16088-3.

Paulraj Rajamani

paulrajr@yahoo.com

1 School of Environmental Sciences, Jawaharlal Nehru University, New Delhi 110067, India 